\title{
Cloning and sequencing of the genes for the proton-translocating nicotinamide nucleotide transhydrogenase from Rhodospirillum rubrum and the implications for the domain structure of the enzyme
}

\author{
Ross Williams, ${ }^{1}+$ Nick P. J. Cotton, ${ }^{1}$ Christopher M. Thomas ${ }^{2}$ \\ and J. Baz Jackson'
}

Author for correspondence: J. Baz Jackson. Tel: +4421414 5423. Fax: +44214143982.

Schools of Biochemistry ${ }^{1}$ and Biological Sciences², University of Birmingham, Edgbaston, Birmingham B15 2TT, UK
The genes for the proton-translocating nicotinamide nucleotide transhydrogenase from Rhodospirillum rubrum have been cloned using a probe constructed with the polymerase chain reaction, genomic DNA as target and oligonucleotide primers corresponding to amino acid sequence obtained from the purified soluble subunit. There is a cluster of three genes, designated pntAA, pntAB and pntB, whose translation products indicate polypeptides of 384, 139 and 464 amino acids, respectively. This contrasts with the situation in the enzymes from Escherichia coli (two polypeptides) and bovine mitochondria (one polypeptide) but there is close similarity between the sequences. PntAA is the soluble subunit of the enzyme from $R$. rubrum, equivalent to the relatively hydrophilic domain I that forms the $\mathrm{N}$-terminal part of the $\alpha$ polypeptide of $E$. coli transhydrogenase and which probably contains the NAD(H)-binding site. PntAB corresponds to the strongly hydrophobic domain lla at the C-terminus of the $\alpha$ polypeptide of the $E$. coli transhydrogenase. PntB corresponds to the $E$. coli $\beta$ polypeptide, which comprises the strongly hydrophobic domain Ilb and the relatively hydrophilic domain III, thought to contain the NADP(H)-binding site. The peptide bond between PntAA-Lys237 and -Glu238 of both the denatured and the native soluble subunit is very sensitive to proteolysis by trypsin and the neighbouring peptide bond Lys227-Thr228 to cleavage by the endoproteinase Lys-C. Related sites have been reported to be sensitive to trypsin in the $E$. coli and bovine mitochondrial enzymes. The two tryptic fragments from the native $R$. rubrum soluble subunit are unable to reconstitute transhydrogenase activity to membranes depleted of the soluble subunit but they can block reconstitution by intact soluble subunit. It is suggested that this protease-sensitive region separates two subdomains and that, after trypsinolysis, at least one retains structural integrity and can dock with domains II and/or III.

Keywords: transhydrogenase, gene cloning, gene sequencing, proton translocation, Rbodospirillum rubrum
†Present address: Department of Histopathology, Hammersmith Hospital, Ducane Road, London, W12 ONN, UK.

Abbreviations: $\mathrm{H}^{+}$-Thase, proton-translocating, nicotinamide nucleotide transhydrogenase, EC 1.6.1.1; $\mathrm{Th}_{\mathrm{s}}$, the soluble subunit of transhydrogenase from $R$. rubrum; $C_{T}$-particles, chromatophores of $R$. rubrum depleted of the soluble transhydrogenase subunit by washing; IVR, inverted repeat sequence.

The GenBank accession number for the nucleotide sequence reported in this paper is U05294.

\section{INTRODUCTION}

Transhydrogenase $\left(\mathrm{H}^{+}\right.$-Thase), from the inner membranes of animal mitochondria and the cytoplasmic membranes of many bacteria, couples the transfer of reducing equivalents between $\mathrm{NAD}(\mathrm{H})$ and $\mathrm{NADP}(\mathrm{H})$ to the translocation of protons:

$\mathrm{NADH}+\mathrm{NADP}^{+}+\mathrm{H}^{+}{ }_{\text {out }} \leftrightarrow \mathrm{NAD}^{+}+\mathrm{NADPH}+\mathrm{H}^{+}{ }_{\text {in }}$ 
Thus, in intact mitochondria and bacteria, the imposition of a transmembrane proton electrochemical gradient, for example through the action of a respiratory or photosynthetic electron-transport chain, drives the reaction to the right (Rydstrom et al., 1987; Jackson, 1991; Hatefi \& Yamaguchi, 1992).

The amino acid sequences of $\mathrm{H}^{+}$-Thase from Escherichia coli (Clark et al., 1986; Ahmad et al., 1992) and bovine mitochondria (Yamaguchi et al., 1988) have been predicted from the nucleotide sequences of the genes (pnt $A$ and $p n t B$ ) and the cDNA, respectively. The E. coli enzyme is composed of two polypeptides (molecular masses $54 \mathrm{kDa}$ and $49 \mathrm{kDa}$ ). When their amino acid sequences are lined up contiguously (the $\mathrm{C}$-terminus of $\alpha$ to the $\mathrm{N}$ terminus of $\beta$ ), there is close similarity with the sequence of the single polypeptide ( $109 \mathrm{kDa})$ of the bovine enzyme (approximately $52 \%$ identity). Hydropathic profiles (Clarke et al., 1986; Yamaguchi et al., 1988) indicate that $\mathrm{H}^{+}$-Thase has three large domains. In the bovine enzyme the approximate positions of these domains are from residue 1 to 431 (domain I), from residue 432 to 836 (domain II) and from residue 837 to 1043 (domain III). In E. coli $\mathrm{H}^{+}$-Thase the 'break' between the two polypeptides is located in domain II. For reasons that will become clear, it is appropriate to consider that domain II is composed of two subdomains; the part of domain II on the $\alpha$ polypeptide of E. coli (or its homologues), will be denoted domain IIa, and the part of the $\beta$ polypeptide (or its homologues) as domain IIb.

Domain II (both IIa and IIb) of $\mathrm{H}^{+}$-Thase is strongly hydrophobic and might comprise between 12 and 14 transmembrane helices (Clarke et al., 1986; Yamaguchi $e t$ al., 1988; Tong et al., 1991). Domains I and III are relatively hydrophilic; they probably contain the $\mathrm{NAD}^{+} / \mathrm{NADH}$-binding site and the $\mathrm{NADP}^{+} / \mathrm{NADPH}-$ binding site, respectively (Clarke $e$ t al., 1986; Wakabayashi \& Hatefi, 1987a; Yamaguchi et al., 1988; Yamaguchi \& Hatefi, 1993). The susceptibility of $\mathrm{H}^{+}$-Thase to proteases and the nature of the reaction with antibodies suggest that domains I and III both protrude on the matrix side of the membrane in bovine mitochondria (the cytoplasmic side in E. coli: Yamaguchi et al., 1990; Yamaguchi \& Hatefi, 1991; Tong et al., 1991). It was shown (Cunningham $e t$ al., 1992a) that there are strong sequence similarities (approximately $30 \%$ identity) between domain I of $\mathrm{H}^{+}$Thase and the enzyme, alanine dehydrogenase (Kuroda et al., 1990), which catalyses the reversible, reductive amination of pyruvate to alanine.

Recently, the translation of a sequence of cDNA isolated from human brain was found to be homologous with a part of domain IIb of bovine $\mathrm{H}^{+}$-Thase (Adams et al., 1992; Kramer et al., 1993). Sequence identity extends by two amino acid residues into the region which, in the bovine enzyme, forms the short polypeptide link between domains IIa and IIb. This indicates that the gene and polypeptide composition are similar in the two organisms. In contrast, the translation of a polymerase chain reaction product of genomic DNA from the protozoan parasite
Eimeria tenella indicates that this organism has an $\mathrm{H}^{+}$Thase with a different polypeptide and gene structure (Kramer et al., 1993). The full-length coding sequence establishes that $\mathrm{H}^{+}$-Thase from Ei. tenella comprises a single polypeptide, but that the domain order is different to that in the bovine enzyme; from the $\mathrm{N}$-terminus of the protein it proceeds IIb $>$ III $>$ I $>$ IIa. Thus, to observe sequence homology between Ei. tenella and E. coli, the two polypeptides of the bacterial enzyme must be aligned such that the $\mathrm{C}$-terminus of the $\beta$ polypeptides is contiguous with the $\mathrm{N}$-terminus of the $\alpha$. In that arrangement there is $45 \%$ amino acid identity between the sequences of $\mathrm{H}^{+}$-Thase from E. coli and Ei. tenella (Kramer et al., 1993).

Another different polypeptide composition is suggested by analysis of $\mathrm{H}^{+}$-Thase from the photosynthetic bacterium Rbodospirillum rubrum (Cunningham et al., 1992a). In this organism, the enzyme can be resolved, under mild conditions, into a water-soluble component (formerly known as $T h_{s}$ ) and a membrane-bound component (Fisher \& Guillory, 1971a, b; Cunningham et al., 1992a). Separately, neither component has transhydrogenase activity but the protein can be fully reconstituted in the presence of nucleotides (Cunningham et al., 1992b). The $\mathrm{N}$-terminal amino acid sequence and the molecular mass of the purified soluble transhydrogenase subunit indicated that it probably corresponds to domain $\mathrm{I}$ of $\mathrm{H}^{+}$-Thase (Cunningham et al., 1992a). In this report we describe the sensitivity of $\mathrm{Th}_{\mathrm{s}}$ to proteases, the cloning and sequencing of the genes for $\mathrm{H}^{+}$-Thase from $\mathrm{R}$. rubrum and the implications for the domain structure of the enzyme.

\section{METHODS}

Bacterial strains and growth conditions. R. rubrum strain $\mathrm{S} 1$, from Dr L. Slooten, Vrije Universiteit, Brussels, Belgium, was grown anaerobically under phototrophic conditions on RCV medium (Weaver et al., 1975) at $30^{\circ} \mathrm{C}$ in completely sealed bottles, as described by Cunningham $e t$ al. (1992a). E. coli strain MC1061 [bsdR mcrB araD139 $\Delta($ ara ABC-leu) $7679 \Delta$ lacX74 galU galK $r p s L$ thi; Meissner et al., 1987] was grown with shaking in L-broth, or on L-agar (1.5\%, w/v, agar added to L broth) at $37^{\circ} \mathrm{C}$, as described by Sambrook et al. (1989). Antibiotic resistance was selected by addition of $100 \mu \mathrm{g}$ ampicillin $\mathrm{ml}^{-1}$ to the solid medium.

Biochemical preparations and procedures. Chromatophores (everted membrane vesicles) of $R$. rubrum and $\mathrm{C}_{\mathrm{T}}$-particles (chromatophores washed to remove soluble transhydrogenase subunit) were prepared, and the soluble transhydrogenase subunit was purified and assayed, as described by Cunningham et al. (1992a). Crude soluble subunit (type II $\mathrm{Th}_{\mathrm{s}}$ ) was prepared as in Fisher \& Guillory (1971a). Bacteriochlorophyll was assayed using the in vivo absorption coefficient (Clayton, 1963). Light-driven transhydrogenation was measured by following the reduction of thio-NADP ${ }^{+}$with NADH at $395 \mathrm{~nm}$ using known absorption coefficients (Palmer \& Jackson, 1992).

When $\mathrm{N}$-terminal amino acid sequences of fragments were required, purified soluble transhydrogenase subunit was first subjected to SDS-PAGE. The $43 \mathrm{kDa}$ polypeptide was excised, electro-eluted in $0.05 \%(\mathrm{w} / \mathrm{v}) \mathrm{SDS}$, diluted and incubated 
overnight at $18{ }^{\circ} \mathrm{C}$ with protease (approximately $100: 1$ by mass). The samples were then concentrated, again subjected to SDS-PAGE and electro-blotted on to poly(vinylidine difluoride) membrane. Peptides were visualized with PAGE Blue83, cut out and analysed with an Applied Biosystems 473A gasphase sequencer. Further details of these procedures are described by Palmer et al. (1993). For the reconstitution experiments shown in Fig. 6, purified soluble subunit of $R$. ruburum $\mathrm{H}^{+}$-Thase $(21 \mu \mathrm{g}$ protein), dialysed against $1 \mathrm{mM}$ dithiothreitol, $10 \mathrm{mM}$ Tris $/ \mathrm{HCl} \mathrm{pH} 8.0$, to remove salt and phenylmethylsulphonyl fluoride, was incubated for $5 \mathrm{~h}$ with $0.6 \mu \mathrm{g}$ trypsin in a volume of $0.9 \mathrm{ml}$. The reaction was stopped with $6 \mu \mathrm{g}$ trypsin inhibitor.

In vitro manipulation and analysis of DNA. Genomic DNA from R. rubrum was prepared by a modification of the method of Fitzmaurice et al. (1989), with the following exceptions. The $80 \mathrm{ml}$ overnight culture was grown phototrophically (see above). The bacterial cells, harvested by centrifugation, were washed in $20 \mathrm{mM}$ EDTA, $50 \mathrm{mM}$ Tris $/ \mathrm{HCl} \mathrm{pH} 8.0$, resuspended in $10 \mathrm{ml}$ of the same medium supplemented with $0.5 \%$ SDS and $2.5 \mathrm{mg}$ RNase, and incubated at $37^{\circ} \mathrm{C}$ for $1 \mathrm{~h}$. Proteinase $\mathrm{K}(2.5 \mathrm{mg})$ was added and the incubation was continued at $65^{\circ} \mathrm{C}$ for $3 \mathrm{~h}$. The lysate was extracted twice with phenol/chloroform/isoamyl alcohol (25:24:1, by vol.) and then twice with chloroform/isoamyl alcohol $(24: 1, \mathrm{v} / \mathrm{v})$. Following addition of sodium acetate, the DNA was precipitated with ethanol, removed by spooling, resuspended in sodium acetate, reprecipitated and washed in ethanol.

Plasmid DNA was prepared on both small and large scales by the alkaline-SDS method (Birnboim \& Doly, 1979) and purified, where necessary, by caesium chloride/ethidium bromide equilibrium density-gradient centrifugation. DNA manipulations and the handling of bacteria were carried out by standard techniques (Sambrook et al., 1989). Restriction enzymes were used according to the manufacturers' instructions. Oligonucleotide probes were labelled with $\left[\alpha{ }^{32} \mathrm{P}\right] \mathrm{dCTP}$, as described by Feinberg \& Vogelstein (1984). DNA sequencing was performed both by the dideoxy-chain-termination method (Sanger et al., 1977) with a Sequenase version 2.0 kit from United States Biochemicals, and with an Applied Biosystems Incorporated 373A automated sequencer using the manufacturer's kit employing Taq polymerase and dye terminators according to their instructions.

Computer alignments, using the University of Wisconsin GCG package (Devereux et al., 1984), and searches, were carried out on the Owl database at the Science and Engineering Research Council Facility at Daresbury, and through the Biocomputing Unit at the University of Edinburgh. Hydropathic profiles were determined using a program written by Dr D. A. Rouch, School of Biologial Sciences, University of Birmingham, based on the parameters described by Von Heijne (1992).

Cloning of genes for $\mathbf{H}^{+}$-Thase from $\boldsymbol{R}$. rubrum. On the basis of $\mathrm{N}$-terminal sequence of $\mathrm{Th}_{\mathrm{s}}$ and peptides prepared by proteolysis of $\mathrm{Th}_{\mathrm{s}}$ (Cunningham et al., 1992a), degenerate oligonucleotides were synthesized as primers for the polymerase chain reaction (PCR) using genomic DNA from R. rubrum as a target. The products were re-amplified and sequenced. Comparison with published sequences confirmed that the PCR products were derived from $\mathrm{H}^{+}$-Thase. A restriction map of $R$. rubrum DNA, using labelled PCR product as a probe of Southern blots, is shown in Fig. 1. Bam HI fragments of R. rubrum DNA between 4 and $7 \mathrm{~kb}$ were cloned into pBR322 and used to transform E. coli MC1061. Clones bearing inserts were selected. by colony hybridization, again using labelled PCR product as a probe. Four positive clones were selected, and shown by restriction analysis to contain DNA equivalent to the PCR product. One of these, $\mathrm{pNIC1}$, was used for nucleotide sequencing (see Fig. 1). On the basis of the restriction map of this construct, DNA fragments were subcloned into pUC18 and nucleotide sequences of the $5^{\prime}$ and $3^{\prime}$ ends of the fragments were determined using universal forward and reverse primers. From these sequences oligonucleotides were constructed to serve as

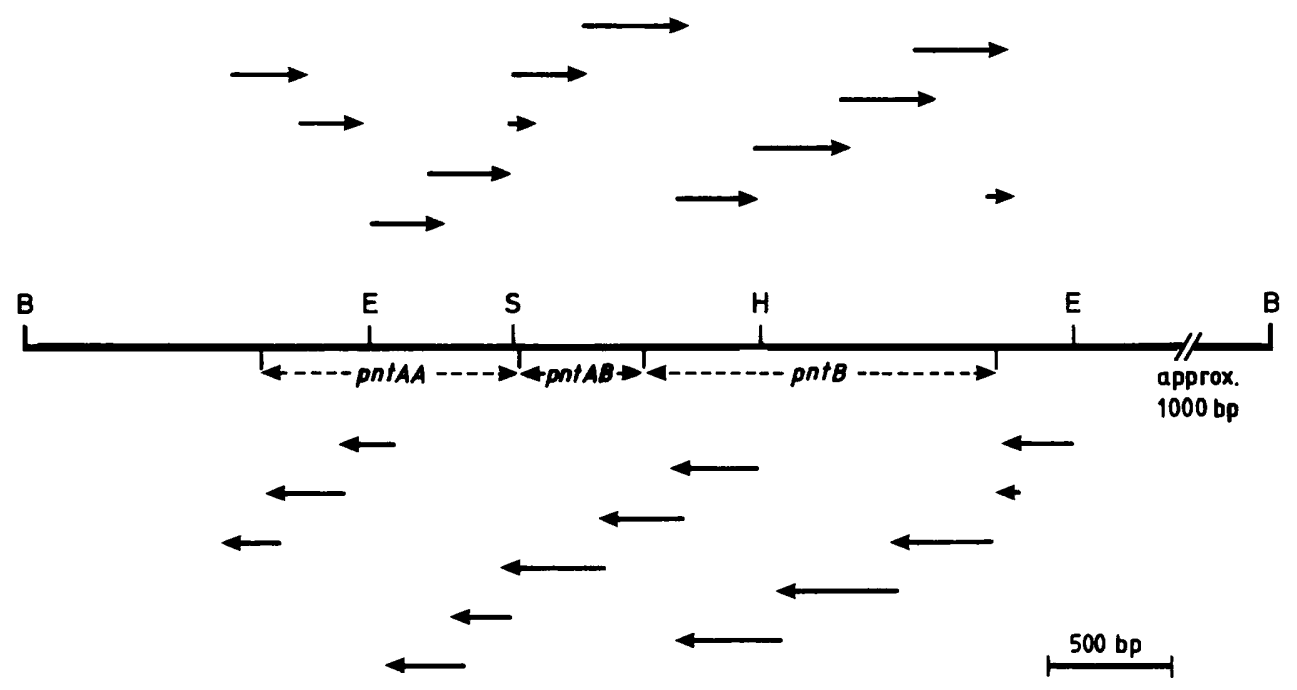

Fig. 1. (a) Restriction map of the $6.1 \mathrm{~kb} B a m H I$ insert of $R$. rubrum DNA obtained by colony hybridization, and (b) the sequencing strategy. E, EcoRI; B, BamHI; S, Sall; H, HindllI. The solid arrows to the left and right show sequences obtained for the top and bottom DNA strands, respectively. The direction of the arrows show the direction of sequencing and the position of the arrows indicates regions over which sequence was obtained using universal forward and reverse, or newly-synthesized primers (see Methods). The dashed arrows indicate the position of the three $\mathrm{H}^{+}$-Thase genes. The numbers of base pairs between the structural genes and the BamHI sites are only approximate. 
primers for further sequencing using either pNIC1 or appropriate subclones in pUC18.

Materials. Nicotinamide nucleotides, TPCK-treated trypsin (T8642) and soybean trypsin inhibitor (T9003) were obtained from Sigma, sequencing-grade Lys-C and Asp-N endoproteinases from Boehringer, restriction enzymes and ligases from Northumbria Biologicals, radiolabelled nucleotides from Amersham, and oligonucleotides from Alta Bioscience.

\section{RESULTS AND DISCUSSION}

\section{Nucleotide sequence of $R$. rubrum pnt genes reveals novel gene organization}

The nucleotide sequence from the cloned Bam HI fragment, and its translation product, are shown in Fig. 2. The pnt genes were assigned by locating regions coding for polypeptides containing sequence identical to that of proteolytic fragments of the soluble subunit of $R$. rubrum $\mathrm{H}^{+}$-Thase, and by similarity to the E. coli pnt genes. There are three ORFs, which we have designated $p n t A A$, pnt $A B$ and pnt $B$ (reasons for this nomenclature will become evident below). Each is preceded by reasonable translational signals and is separated from the adjacent ORF by only 3 and 13 nucleotides, respectively. Downstream of $p n t B$ are two IVRs, both of which are potential $r b o$-independent transcriptional terminators, since they consist of a $\mathrm{G}+\mathrm{C}$-rich hairpin, followed by a run of $\mathrm{A}+\mathrm{T}$-rich sequence (Platt, 1986). Upstream of pnt $A A$ is a region of at least $103 \mathrm{bp}$ which is unlikely to be translated because of the presence of stop codons in all three frames. This region also contains two IVRs which may be involved with transcriptional termination (Platt, 1986) but could also be binding sites for regulatory proteins. These upstream and downstream features probably thus define the pnt genes as a translational unit containing three cistrons. Upstream of pnt $A A$ there is no obvious sequence to fit a consensus for either $\mathrm{E} \sigma^{70}$ or $\mathrm{E} \sigma^{54}$ (Harley \& Reynolds, 1987; Kustu et al., 1989) which can identify the likely promoter, although there clearly would be space for an RNA polymerase binding site. The expression and regulation of these genes will form the basis of a separate study.

The predicted molecular masses of the gene products PntAA, PntAB and PntB are $40 \cdot 3,14.9$ and $47.8 \mathrm{kDa}$, respectively. Analysis and comparison of the predicted amino acid sequences clearly reveal that, in contrast to the one and two polypeptides of bovine mitochondrial and $E$. coli transhydrogenases, respectively, the enzyme from $\mathrm{R}$. rubrum consists of three polypeptides (Fig. 3). Thus, the $\alpha$ polypeptide of $\mathrm{H}^{+}$-Thase of $E$. coli can be viewed as a fusion of the PntAA and PntAB polypeptides of the $R$. rubrum enzyme (from the C-terminus of PntAA to the $\mathrm{N}$ terminus of PntAB); the $\beta$ polypeptide of $E$. coli and the PntB polypeptide of $R$. rubrum are equivalent. On this basis, and on the basis of the previously established relationship between the $E$. coli and bovine enzymes, the alignment shown in Fig. 4 indicates that there is $49.6 \%$ amino acid identity between the E. coli and R. rubrum $\mathrm{H}^{+}$-
Thases and $43.4 \%$ between the R. rubrum and bovine mitochondrial proteins (not shown). There is greater sequence divergence between the $R$. rubrum enzyme and the E. coli and the bovine enzymes than between the E. coli and bovine enzymes ( $52 \%$ identity). This divergence arises mainly in the region of the PntAA polypeptide of $R$. rubrum.

\section{Subunit properties predicted from the Pnt primary amino acid sequences}

Hydropathic profiles of the predicted polypeptides of $R$. rubrum $\mathrm{H}^{+}$-Thase are shown in Fig. 5. Except for the region of the $\mathrm{NAD}(\mathrm{H})$-binding site (see below), PntAA generally has a rather hydrophilic character. Comparison of the $\mathrm{N}$-terminal and internal sequences with the amino acid sequence predicted from the gene establishes unequivocally that this gene product is $\mathrm{Th}_{\mathrm{s}}$. The possibility that $T h_{\mathrm{s}}$ is a proteolytic breakdown product of $\mathrm{H}^{+}$-Thase, which formerly could not be eliminated (Cunningham $e t$ al., 1992a) can now be discounted. Thus, uniquely in $R$. rubrum, domain I can be displaced as a discrete, watersoluble protein by washing from the chromatophore membrane. Interestingly, the region between domains I and II in $\mathrm{H}^{+}$-Thase of E. coli and bovine mitochondria is sensitive to proteolysis by trypsin (Tong et al., 1991; Yamaguchi et al., 1990) and it is possible that, in those systems under non-denaturing conditions, the resulting $43 \mathrm{kDa}$ polypeptides might reconstitute transhydrogenase activity to depleted membranes.

PntAB is a small hydrophobic polypeptide. In the equivalent region (domain IIa) of the bovine and E. coli enzymes, four transmembrane helices were predicted (Yamaguchi et al., 1988; Yamaguchi \& Hatefi, 1991; Tong et al., 1991). Four helices are also indicated in a hydropathy analysis of the sequence from Kramer $e t$ al. (1993) of Ei. tenella transhydrogenase (data not shown). However, the hydropathy profile shown in Fig. 5, which uses the scale of Von Heijne (1992), predicts, with reasonable confidence, that only the last three of these segments are transmembranous in $R$. rubrum PntAB. In an analysis using the amalgamated hydropathy scale of Kyte \& Doolittle (1982), the first putative transmembrane helix (from Ala25 to Thr43) is again only weakly predicted in PntAB (data not shown). If it is assumed that the arrangement of transmembrane helices in the four transhydrogenases is similar, then, in view of the wellconserved cluster of positive charges at the $\mathrm{C}$-terminus of PntAB (residues 129-139), which, by the 'positive-inside rule' should be located on the cytoplasmic side of the membrane (Von Heijne, 1992), and the fact that domain I is assuredly cytoplasmic (Cunningham et al., 1992a), an even number of transmembrane helices in the polypeptide is most likely. Provisionally therefore, it is suggested that the first, weakly predicted transmembrane helix of PntAB should be accepted. It cannot be excluded that the transmembrane helix composition of Pnt $\mathrm{AB}$ is different to the equivalent region in other species but, if there were only three transmembrane helices, the $\mathrm{N}$-terminus of PntAB would probably be located in the periplasm, which 


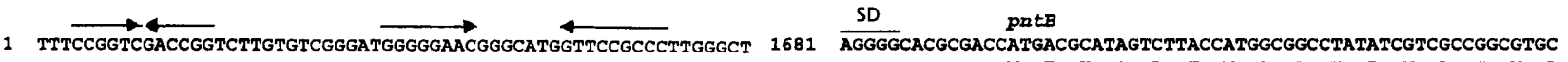

61 CGATAAGACCTragaccGTCTCACGACAATTGATGG SD pntaA

PRtAa $\begin{array}{llllll}M & \mathbf{K} & \boldsymbol{I} & \mathbf{A} & \mathbf{I} & \mathbf{P}\end{array}$

121 AAAAGAGCGACGCCCCGGCGAGGATCGCGTCGCCATCTCTCCCGAGGTGGTGAAGAAGCT \begin{tabular}{llllllllllllllllllll}
$\mathbf{R}$ & $\mathbf{E}$ & $\mathbf{R}$ & $\mathbf{R}$ & $\mathbf{P}$ & $\mathbf{G}$ & $\mathbf{E}$ & $\mathbf{D}$ & $\mathbf{R}$ & $\mathbf{V}$ & $\mathbf{A}$ & $\mathbf{I}$ & $\mathbf{S}$ & $\mathbf{P}$ & $\mathbf{E}$ & $\mathbf{V}$ & $\mathbf{V}$ & $\mathbb{R}$ & $\mathbb{R}$ & $\mathbf{L}$ \\
\hline
\end{tabular}

181 CGTCGGCCTGGGGTTCGAGGTGATCGTCGAACAAGGGGCCGGTGTCGGCGCGTCGATAAC $\begin{array}{llllllllllllllllllll}V & G & \text { L } & G & F & E & V & I & V & E & Q & G & A & G & V & G & A & S & I & T\end{array}$

241 CGACGATGCCTTGACCGCCGCCGGCGCCACCATCGCCAGCACGGCGGCGCAGGCCCTGTC $\begin{array}{llllllllllllllllllll}D & D & A & L & T & A & A & G & A & T & I & A & S & T & A & A & Q & A & I & S\end{array}$

301 CCAGGCCGATGTGGTCTGGAAGGTACAGCGGCCGATGACCGCCGAGGAGGGCACCGACGA $\begin{array}{llllllllllllllllllll}Q & A & D & V & V & \text { W } & K & V & Q & R & P & M & T & A & E & E & G & T & D & E\end{array}$

361 GGTCGCCCTGATCAAGGAAGGGCGGTCCTGATGTGCCATCTTGGCGCCCTGACCAACCG $\begin{array}{lllllllllllllllllllll}V & A & \text { L } & \text { I } & \text { K } & \text { E } & G & \text { A } & \text { V } & \text { L } & \text { M } & \text { C } & \text { H } & \text { L } & \text { G } & \text { A } & \text { L } & \text { T } & \text { N } & R\end{array}$

421 TCCGGTGGTCGAGGCCCTGACCAAGCGCAAGATCACCGCCTATGCCATGGAACTGATGCC

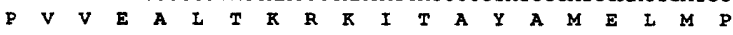

TGGGCATGGTCGGCATGGCGATCGCCATCCTGACCACGCTGCTGTCGCCTTCGGTTCAGG $\begin{array}{llllllllllllllllllll}G & M & V & G & M & A & I & A & I & L & T & T & I & I & S & P & S & V & Q & A\end{array}$ CCTATGCCTGGATCGTCCTGGCGATCGCCATCGGCGGCGCCATCGGCACGGTGATCGCCA

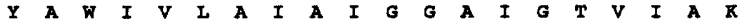

AAAAGGTGCTGATGACCGCCCTGCCGCAGCTTGTCGCCGCCTTCCACTCGCTGGTCGGCA

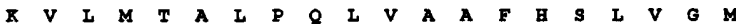
1981 TGGCCGCCGTGCTGGTGGCCACCGGCGCCCTGCTCAATCCCGAAGCCTATGGCATCGGTT

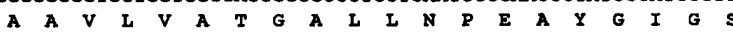

2041 CGGCCGGGGCGATCCACGCCGGATCGCTGGTTGAAATGTCGCTCGGCCTGGCCGTCGGCG

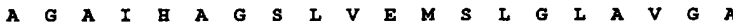
2101 CCATCACCTTCTCGGGATCGGTGATCGCCTYTGGCAAGCTTCAGGGGCTGATCGCCGGCA $\begin{array}{llllllllllllllllllll}I & T & F & S & G & S & V & I & A & F & G & K & I & Q & G & I & I & A & G & K\end{array}$

481 GCGGATCAGCCGCGCCCAGTCGATGGATATCCTTTCCAGCCAGTCGAACCTCGCGGGCTA $\begin{array}{llllllllllllllllllll}R & I & S & R & A & Q & S & M & D & I & L & S & S & Q & S & \text { N } & \text { L } & \text { A } & G & \text { Y }\end{array}$

AGCCGGTGACCTTCCCGATGCAGCATCCGCTGAACGCCGTGCTTGGCATTCTGCTGGTCG $\begin{array}{lllllllllllllllllllll}P & V & T & F & P & M & Q & B & P & I & N & A & V & I & G & I & L & I & V & V\end{array}$

541 TCGCGCCGTGATCGACGGCGCTTATGAATTCGCCCGCGCCTTTCCGATGATGATGACCGC

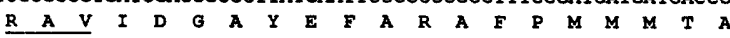

601 CGCCGGCACCGTGCCGCCGGCCCGCGTGCTGGTGTTTGGCGTCGGCGTCGCCGGATTGCA $\begin{array}{lllllllllllllllllllll}\text { A } & G & \text { T } & \text { V } & \text { P } & \text { P } & \text { A } & \text { R } & \text { V } & \text { L } & \text { V } & \text { F } & \text { G } & \text { V } & \text { G } & \text { V } & \text { A } & \text { G } & \text { L } & 0\end{array}$

661 GGCGATCGCCACGGCCAAGCGCCTGGGCGCCGTGGTCATGGCCACCGACGTTCGCGCCGC $\begin{array}{llllllllllllllllllll}\mathbf{A} & I & \mathbf{A} & \mathbf{I} & \mathbf{A} & \mathbf{K} & \mathbf{R} & \mathbf{L} & G & \mathbf{A} & \mathbf{V} & \mathbf{V} & \mathbf{M} & \mathbf{A} & \mathbf{T} & \mathbf{D} & \mathbf{V} & \mathbf{R} & \mathbf{A} & \mathbf{A}\end{array}$

721 CACCAAGGAACAGGTGGAAAGCCTGGGCGGCAAGTTCATCACCGTCGATGACGAGGCGA

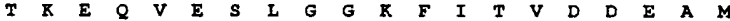

781 GAAGACCGCCGAGACCGCCGGCGGCTACGCCAAGGAAATGGGCGAGGAGTTCCGCAAGAA

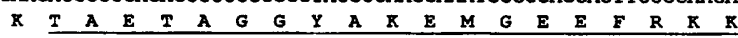

841 GCAGGCCGAGGCCGTGCTCAAGGAACTGGTCAAGACCGATATCGCCATCACCACCGCCC $\begin{array}{llllllllllllllllllll}\mathbf{Q} & \mathbf{A} & \mathbf{E} & \mathbf{A} & \mathbf{V} & \mathbf{L} & \mathbf{K} & \mathbf{E} & \mathbf{L} & \mathbf{V} & \mathbf{K} & \mathbf{T} & \mathbf{D} & \text { I } & \mathbf{A} & \text { I } & \mathbf{T} & \mathbf{T} & \mathbf{A} & \mathbf{L}\end{array}$

901 GATCCCCGGCAAGCCCGCGCCGGTGCTGATCACCGAGGAGATGGTGACCAAGATGAAGCC $\begin{array}{llllllllllllllllllll}I & P & G & K & P & A & P & V & I & I & T & E & E & M & V & T & K & M & K & P\end{array}$

961 GGGCAGCGTCATCATCGATCTGGCCGTCGAAGCCGGCGGCAATTGCCCGCTGTCGGAGC $\begin{array}{lllllllllllllllllllll}G & S & V & I & I & D & \text { L } & A & V & E & A & G & G & \text { N } & C & \text { P } & \text { L } & \text { S } & \text { E } & \text { P }\end{array}$

1021 GGGCAAGATCGTTGTCAAACACGGCGTCAAGATCGTTGGCCACACCAACGTCCCCTCGCG $\begin{array}{llllllllllllllllllll}G & K & I & V & V & K & H & G & V & R & I & V & G & A & T & N & V & P & S & R\end{array}$

1081 CGTCGCCGCCGACGCCAGCCCGTTGTTCGCCAAGAACCTTCTGAACTTCCTCACCCCCCA $\begin{array}{lllllllllllllllllllll}V & A & A & D & A & S & \text { P } & \text { L } & \text { F } & \text { A } & \text { K } & \text { N } & \text { L } & \text { L } & \text { N } & \text { F } & \text { L } & \text { T } & \text { P } & \text { H }\end{array}$

1141 CGTCGACAAGGACACGAAGACGCTGGTGATGAAGCTCGAGGACGAAACGGTTTCGGGCAC

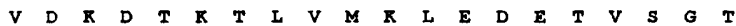

$\begin{array}{lllllllllllllllllllll} & \text { V } & \text { D } & \text { K } & \text { D } & \text { T } & \text { K } & \text { T } & \text { L } & \text { V } & \text { M } & \text { K } & \text { L } & \text { E } & \text { D } & \text { E } & \text { T } & \text { V } & \text { S } & G & T \\ 1201 & \text { CTGTGTGACCCGCGATGGCGCCATCGTCCATCCGGCGCTGACCGGACAGGGAGCATAAGC }\end{array}$ $\begin{array}{llllllllllllllllllll}C & V & T & R & D & G & A & I & V & H & P & A & L & T & G & Q & G & A\end{array}$ pntas

1261 GATOGMGACMAGMACATCCTCOTCGAGGGCTTCAATCAGCTCTCGCAACAGGCCCTTGA

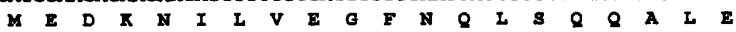

1321 ATTOTCCCAGCATOCCCAGOCCCTOOCCCTTCAGOCCAGCCATGCGOTTCTGCCGOCCOC

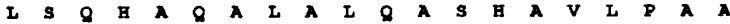

1381 COCCOCCACGGAAGCGCCAGCGAGTTCTGGTGGCTGATGACGGTTTTCGTCCTGGCCTO

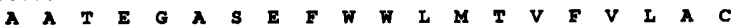

1441 CTTCATCGGCTTITATGTGGTGTGGTCGGTGACCCCGGCCCTTCACAGCCCGCTGATGG

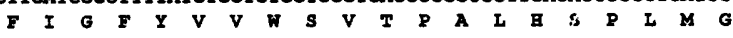

2221 TGCTGCTGGTGGTCTTCGCCGCCACCGAAAGCCACACCGCCTATTTCGCCCTGATGATCC $\begin{array}{lllllllllllllllllllll} & I & V & V & F & A & A & T & E & S & B & T & A & Y & F & A & I & M & I & I\end{array}$

2281 TGGCCTTCGCCCTTGGCTTCTTGCTGATCATTCCGATCGGCGGCGCCGACATGCCGGTCG $\begin{array}{llllllllllllllllllll}A & F & A & I & G & F & \text { I } & \text { I } & \text { I } & \text { I } & \text { P } & \text { I } & G & G & \text { A } & \text { D } & \text { M } & \text { P } & \text { V } & \text { V }\end{array}$

2341 TCATCTCGATGCTCAACAGCTATTCGGGCTGGGCGGCTGCGGGCATTGGCTTCACCCTGG I $S$ S M I I 2401 GCAATCCGCTGCTGATCATCGCCGGCGCCCTGGTCGGGTCGTCGGGCGCCATCCTCAGCT $\begin{array}{llllllllllllllllllll}\text { N } & P & \text { I } & \text { I } & \text { I } & \text { I } & \text { A } & G & A & \text { I } & V & G & S & S & G & A & I & I & S & Y\end{array}$

2461 ACATCATGTGCAAGGGCATGAACCGCTCGATCTTCAACGTCATCCTGGGCGGTPCGGCA

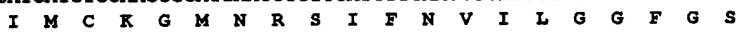
2521 GCGAGGGCGGCGTAGCGGCGGCCGGTGGCGCGGCCGGCGATCGTTCGGTCAAGGCCGGCA

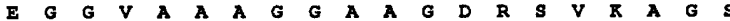

2581 GCGCCGAAGACGCGGCCTTCATCATGAAGAACGCCTCGAAGGTCATCATCGTGCCCGGCT

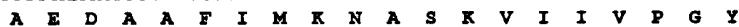
2641 ATGGCATGGCGGTGGCCCAGGCCCAGCACGCCCTGCGCGAAATGGCCGATGTGCTCAAGA

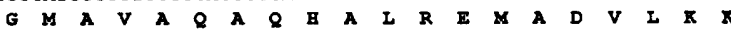

2701 AgGAagGGTCGAGgTTTCCTACGCCATCCATCCGGTGGCCGGCCGTATGCCCGGGCATA

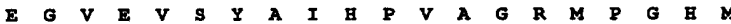

2761 TGAACGTGCTGCTGGCCGAGGCCAATGTGCCCTATGACGAGGTCTTCGAGCTCGAAGAGA $\begin{array}{llllllllllllllllllll}\mathbf{N} & V & \mathbf{L} & \mathbf{L} & \mathbf{A} & \mathbf{E} & \mathbf{A} & \mathbf{N} & \mathbf{V} & \mathbf{P} & \mathbf{Y} & \mathbf{D} & \mathbf{E} & \mathbf{V} & \mathbf{F} & \mathbf{E} & \mathbf{L} & \mathbf{E} & \mathbf{E} & \mathbf{I}\end{array}$

2821 TCAACAGCTCGTTCCAGACCGCCGATGTCGCCTTCGTCATCGGCGCCAACGACGTGACCA

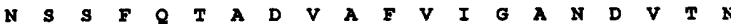

2881 ACCCGgCGgCCAAGACCGATCCGTCGAGCCCGATCTACGgCATGCCGATCCTTGACGTTG

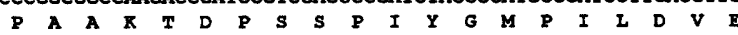

2941 AAAAGGCCGGAACCGTGCTGTTCATCAAGCGCTCGATGGCCTCGGGCTATGCCGGCGTCG $\begin{array}{lllllllllllllllllll} & A & G & T & V & I & F & I & R & R & S & M & A & S & G & Y & A & G & V\end{array}$ 3001 AGAACGAACTGTTCTTCCGCAACAACACGATGATGCTGTTTGGCGACGCCAAGAAGATGA

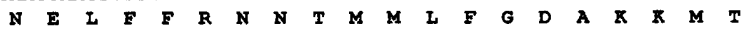
3061 ccGagcagatcgtccaggcgatgaActgaccgcttgagagcggtcattgattacganaAa

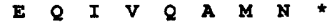

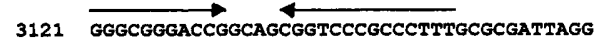

1501 COTCACCAACGCCATTTCCTCGGTCATCGTCGTCGGGGCGCTGATCGCCACCGGTCCTGA

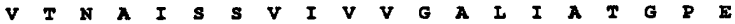

1561 AGCCTTCAGCGCGTCGAAGGTGCTGGGCTTCTTCGCCATCCTGCTTGCGAGCGTGAACAT $\begin{array}{llllllllllllllllllll}A & F & S & A & S & K & V & L & G & F & F & A & I & I & I & A & S & V & N & I\end{array}$

1621 CTTCGGCGGGTTCATCGTGACCCAACGAATGCTGGCCATGTTCAAGAAGAAGCAGAAGTĀ $F$ G $T$ I T O R M I A Y T $T$ T

Fig. 2. Nucleotide sequence of the pntAA, pntAB and pntB genes of $H^{+}$-Thase from $R$. rubrum and their predicted translation products. Probable Shine-Dalgarno sequences are indicated by horizontal lines above the nucleotide sequence. Inverted repeats are indicated by pairs of arrows. The $\mathrm{N}$-terminal sequences of the soluble subunit of $\mathrm{H}^{+}$-Thase and its proteolytic fragments (Cunningham et al., 1992a) are shown with solid lines under the amino acid sequence. The sequence of one of the proteolytic fragments, DILSSQSNLAGYRAV, obtained with endoproteinase Asp- $\mathrm{N}$, has not been previously published. 


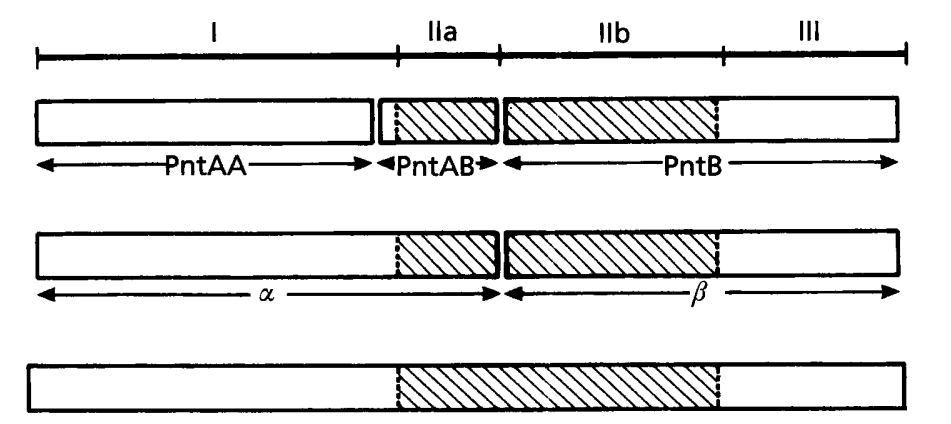

\section{Domain \\ R. rubrum}

E. coli

Bovine

mitochondria

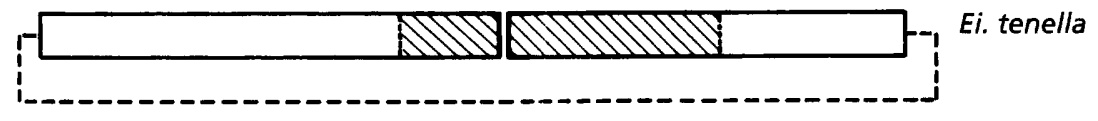

B. stearothermophilus alanine dehydrogenase

Fig. 3. Comparison of the domain and polypeptide structures of $\mathrm{H}^{+}$-Thase from $R$. rubrum, E. coli, bovine mitochondria and Ei. tenella and with alanine dehydrogenase from Bacillus stearothermophilus. Unshaded domains are relatively hydrophilic; shaded domains are strongly hydrophobic. The dashed line linking domains III and I of the Ei. tenella protein represents a linker of 38 amino acid residues (Kramer et al., 1993).

seems unlikely as it does not possess a recognizable signal sequence (see Von Heijne, 1986).

PntB, homologous to the $\beta$ subunit of E. coli $\mathrm{H}^{+}$-Thase, has a strongly hydrophobic domain IIb (Fig. 5), and a relatively hydrophilic domain III, which, by analogy, probably protrudes from the membrane on the cytoplasmic side (Yamaguchi et al., 1990; Yamaguchi \& Hatefi, 1991; Tong et al., 1991). Using the analysis of Kyte \& Doolittle (1982), eight transmembrane helices were predicted for the E. coli $\beta$ subunit (Tong et al., 1991). The equivalent helices are clearly recognizable in the hydropathic profile of PntB of R. rubrum (Fig. 5). If the conclusion (above) is correct, that PntAB has four transmembrane helices, and if the assumption, that the bovine, E. coli and R. rubrum enzymes have a similar arrangement of transmembrane helices, is to be maintained, then an even number of helices for PntB (and $E$. coli $\beta$ subunit) is indeed to be expected. It was predicted that the homologous region of bovine mitochondrial $\mathrm{H}^{+}-$ Thase has ten transmembrane helices (Yamaguchi et al., 1988; Yamaguchi \& Hatefi, 1991). One of these was proposed within the sequence, unique to bovine $\mathrm{H}^{+}$Thase, that forms the link between the equivalent of $R$. rubrum Pnt $\mathrm{AB}$ and PntB (or the $\alpha$ and $\beta$ subunits of the $E$. coli enzyme). The sequence is also absent in $\mathrm{H}^{+}$-Thase from Ei. tenella (Kramer et al., 1993) and the suggestion that it constitutes a transmembrane helix should perhaps be treated with some reservation. The other 'extra' putative transmembrane helix in mitochondrial $\mathrm{H}^{+}$-Thase (Yamaguchi et al., 1988; Yamaguchi \& Hatefi, 1991) can, in fact, be accommodated in the hydropathic profiles of the $E$. coli $\beta$ and the $R$. rubrum PntB polypeptides (e.g. residues 215-233 in the latter). However, an odd number of transmembrane helices would challenge our assump- tion that the arrangement is similar in all the known enzymes. The dilemma is heightened by a consideration of the charged residues in predicted loops lying between putative transmembrane helices. Thus, only one (148-164 in PntB) has a preponderance of Arg and Lys residues in $\mathrm{H}^{+}$-Thase from all four species. Taking PntB from $\mathrm{R}$. rubrum in isolation, only two of the possible loops in domain IIa have net positive charge (one, adjacent to the two Lys residues at positions 76 and 77 , and the other at residues 148-164). Assuming that these loops, the $\mathrm{N}$ terminus and the $\mathrm{C}$-terminus of $\mathrm{PntB}$ are all cytoplasmic, this fits comfortably with the inclusion (at residues 215-233) of the 'extra' transmembrane helix described by Hatefi and colleagues in the mitochondrial enzyme (see above). However, it would also require either that one of the first four predicted transmembrane helices, identified in the hydropathy profile, is in error, or that the $\mathrm{N}$ terminus of the polypeptide is periplasmic rather than cytoplasmic (though it has no recognizable signal sequence). Clearly more evidence is required before firm conclusions can be drawn.

The membrane-bound component of $\mathrm{H}^{+}$-Thase from $\mathrm{R}$. rubrum proved difficult to purify (Palmer et al., 1993), partly because it is a relatively minor protein in chromatophore membranes, but also because of the very stringent detergent requirement to achieve solubilization without inactivation (the ability to reconstitute transhydrogenase activity with the water-soluble subunit): possibly PntAB is easily separated from PntB by many of the commonly used detergents. In routine preparations of the membranebound component of $\mathrm{R}$. rubrum $\mathrm{H}^{+}$-Thase, polypeptides with apparent molecular mass of $50 \mathrm{kDa}, 52 \mathrm{kDa}$ and $56 \mathrm{kDa}$ were observed on SDS-PAGE (Palmer et al., 1993), and are likely candidates for PntB, but they were 
1

Ec ............. MRIGIPR ERLTNETRVA ATPKTVEQLL KLGFTVAVES BO CSAPVKPGIP YKOLTVGVPK EIFONEKRVA LSPAGVOALV KOGFNVVVES Rr ............MKIAIPK ERRPGEDRVA ISPEVVKKLV GLGFEVIVEO AlaDH ............MKIGIPK EIKNNENRVA ITPAGVMTLV KAGHEVYVET

51 GAGQLASFDD KAFVQAGAEI V...EGNSVWO SEIILKVNAP L...... 100 GAGEASKFSD DHYRAAGAOI . EGNSWW SEIILKVNAP L....... DDE GAGEASKFSD DHYRAAGAQI Q..GAKEVLA SDLVVKVRAP MLNPTLGVHE EGGAGSGFSD SEYEKAGAAD RCRTWRDAWT AEMVLKVKEP L......ARE 101

150

IALLNPGTTL VSFIWPAQNP ELMQKLAERN VTVMAMDSVP RISRAQSLDA ADLLKTSGTL ISFIYPAQNP DLLNKLSKRK TTVLAMDQVP RVTIAQGYDA VALIKEGAVL MCHLGALTNR PVVEALTKRK ITAYAMELMP RISRAQSMDI FRYFRPGLIL FTYLHLAAAE RVTKAVVEQK VVGIAYETVQ LAN..GSLPL

151

200

LSSMANIAGY RAIVEAAHEF GRFFTG...Q ITAAGKVPPA KVMVIGAGVA LSSMANIAGY KAVVLAANHF GRFFTG...Q ITAAGKVPPA KILIVGGGVA LSSQSNLAGY RAVIDGAYEF ARAFPM....M MTAAGTVPPA RVLVFGVGVA LTPMSEVAGR MSVQVGAQFL EKPHGGKGIL LGGVPGVRRG KVTIIGGGTA

201

250

GLAAIGAANS LGAIVRAFDT RPEVKEQVQS MGAEFLELD. .FKEEAGSGD GLASAGAAKS MGAIVRGFDT RAAALEQFKS LGAEPLEVD. . LKESGEGQG GLOAIATAKR LGAVVMATDV RAATKEOVES LGGKFITVDD EAMKTAETAG GTNAAKIGVG LGADVTILDI NAERLRELDD LFGDHVT... $\ldots \ldots \ldots \ldots$

$\begin{array}{lr}251 & 300 \\ \text { GYAKVMSDAF IKAEMELFAA QAKEVDIIVT TALIPGKPAP KLITREMVDS }\end{array}$ GYAKVMSDAF IKAEMELFAA QAKEVDIIVT TALIPGKPAP KLITREMVDS GYAKEMSKEF IEAEMKLFAQ QCKEVDILIS TALIPGKKAP ILFNKEMIES GYAKEMGEEF RKKQAEAVLK ELVKTDIAIT TALIPGKPAP VLITEEMVTK 301

301350 MKAGSVIVDL AAQNGGNCEY TVP....GEI FTTENGVKVI GYTDLPGRLP ...GEL $Y$.VHKGITHI GYTDLPSRMA MKPGSVIIDL AVEAGGNCPL SEP ....GKI .VVKHGVKIV GHTNVPSRVA
MTPGSVLVDI AIDQGGIFET TDRVTTHDDP TYVKHGVVHY AVANHPGAVP

351
TOSSOLYGTN LVNLLKLICK EKDG...NIT VDFD. . . . DV VIRGVTVIRA TOASTLYSNN ITKLLKAISP DKDNFYFEVK DDFDFGTMGH VIRGTVVMKD ADASPLFAKN LLNFLTP.HV DKDTKTLVMK LE......DE TVSGTCVTRD .RTSTFALTN VTIPYALQIA NKGYRAGCLD .......... AP ALLKGINTLD

401

GEITWPAP.P IOVSAQPQAA QKAAPEVKTE EKCTCSPWRK Y..... ALMA GQVIFPAPTP KNIPQGAPVK QKTVAELEAE KAATITPFRK TMTSASVYTA GAIVHPALT. ...GQGA $\star M E$ DKNILVEGFN QLSQQALELS QHAQALALQA GHIVYEA... . . VAAAHNMP YTDVHSLLHG *

451

LAIILFGWMA SVAPKEFLGH FTVFALACVV GYYVVWNVSH ALHTPLMSVT GLTGILGLGI AAPNLAFSQM VTTFGLAGIV GYHTVWGVTP ALHSPLMSVT
501

NAISGIIVVG ALLQIGQGGW VSF....LSF IAVLIASINI FGGFTVTORM NAISGLTAVG GLVLMGGHLY PSTTSQGLAA LATFISSVNI AGGFLVTORM NAISSVIVVG ALIATGPEAF SA..SKVLGF FAILLASVNI FGGFIVTORM

551

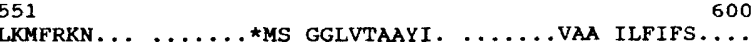
LDMFKRPTDP PEYNYLYLLP AGTFVGGYLA SLYSGYNIEQ IMYLGSGLCC LAMFKKKQK. .......MT HSLTMAAYI. ......VAG VLPIL.... 601 650 ... LAGLSKH ETSRQGNNFG IAGMAIALIA TI.. FGPDTG NVGWILIAMV VGALAGLSTQ GTARLGNALG MIGVAGGLAA TLGGLKPCPE LLAQMSGAMA ..ALRGLSNP ESARNGNRMG MVGMAIAILT TL..LSPSVQ AYAWIVLAIA 651 700

IGGAIGIRLA KKVEMTEMPE LVAILHSFVG LAAVLVGFNS YL.... HHDA LGGTIGLTIA KRIOISDLPO LVAAFHSLVG LAAVLTCIAE YIIEYPHFAT IGGAIGTVIA KKVIMTALPQ LVAAFHSLVG MAAVLVATGA . LLNPEAYGI 701 DAAANLTKI. .. VAYLGTYI GGVTFSGSLV AYGKLOGILK SAPLLLPGRH GSAGAIHAGS LVEMSLGLAV GAITFSGSVI AFGKLQGLIA GKPVTFPMQH 751 800 KMNLAALVVS FLLLIVFVRT DSVGLOVLAL LIMTAIALVF GWHLVASIGG LINAGLLAGS VGGIIPFMMD PSFTTGITCL GSVSALSAVM GVTLTAAIGG LLNAGLLAGS VGGIIPFMMD PSFTTGITCL GSVSALSAVM GVTLTAAIGG 801

ADMPVVVSYI ADMPVVIIVL NSYSGWALCA AGFMLSNDLL IVTGALVGSS GAILSYIMCK ADMPVVITVL NSYSGWALCA EGFLL.NNNLL TIVGALIGSS GAILSYIMCV

851

900

AMNRSFISVI AGGFGTDGSS TGDDQEV.G. EHREITAEET AELLKNSHSV AMNRSLANVI LGGYGTTSTA GGKPMEISG. THTEINLDNA IDMIREANSI GMNRSIFNVI LGGFGSEGGV AAAGGAAGDR SVKAGSAEDA AFIMKNASKV

901

950

IITPGYGMAV AQAQYPVAEI TEKLRARGIN VRFGIHPVAG RLPGHMNVLI IITPGYGLCA AKAQYPIADL VKMLSEQGKK VRFGIHPVAG RMPGQLNVLI IIVPGYGMAV AQAOHALREM ADVLKKEGVE VSYAIHPVAG RMPGHMNVLI

951

1000

AEAKVPYDIV LEMDEINDDF ADTDTVLVIG ANDTVNPAAQ DDPKSPIAGM AEAGVPYDIV LEMDEINHDF PDTDLVLVIG ANDTVNSAAQ EDPNSIIAGM AEANVPYDEV FELEEINSSF QTADVAFVIG ANDVTNPAAK TDPSSPIYGM

1001

1050

PVLEVWKAQN VIVFKRSMNT GYAGVQNPLF FKENTHMLFG DAKASVDAIL PVLEVWKSKQ VIVMKRSLGV GYAAVDNPIF YKPNTAMLLG DAKKTCDALQ PILDVEKAGT VLFIKRSMAS GYAGVENELF FRNNTKMLFG DAKKMTEQIV

1051

KAL*......

AKVRESYOK

QAMN*....

Fig. 4. Alignment of the predicted amino acid sequences of $\mathrm{H}^{+}$-Thase from $E$. coli (EC), bovine mitochondria (Bo) and $R$. rubrum (Rr), and alanine dehydrogenase from $B$. stearothermophilus (AlaDH).

obtained in insufficient quantities for $\mathrm{N}$-terminal sequencing. Polypeptides with a molecular mass corresponding to that of PntAB were not detected on SDSPAGE, again indicating that this component might be easily lost during purification.

\section{The nucleotide-binding sites of $\mathbf{H}^{+}$-Thase}

There is presently consideable interest in the nature and location of the $\mathrm{NAD}(\mathrm{H})$ - and the $\mathrm{NADP}(\mathrm{H})$-binding sites on $\mathrm{H}^{+}$-Thase. The $\beta-\alpha-\beta$ Rossman fold, characteristic of ADP/FAD binding sites (Wierenga et al., 1986), and thought to represent the $\mathrm{NAD}(\mathrm{H})$-binding site in $\mathrm{H}^{+}$Thase (Clarke et al., 1986; Yamaguchi et al., 1988), is strongly conserved in PntAA, centred on the Gly-X-Gly$\mathrm{X}$-X-Gly motif at residues 179-184. Tyr245 in mitochondrial $\mathrm{H}^{+}$-Thase reacts with the $\mathrm{NAD}(\mathrm{H})$ analogue [ $p$-(fluorosulphonyl)benzoyl]-5'-adenosine (Wakabayashi \& Hatefi, 1987a) and is conserved in PntAA (Tyr235), although replacing the equivalent residue in $E$. coli by sitedirected mutagenesis indicates that it is not essential (Olausson et al., 1993). Similarly, it has been argued (Wakabayashi \& Hatefi, 1987b) that Glu257 in the mitochondrial $\mathrm{H}^{+}$-Thase, which, in the absence of $\mathrm{NAD}(\mathrm{H})$, reacts with $N, N^{\prime}$-dicyclohexylcarbodiimide, might lie at or near the $\mathrm{NAD}(\mathrm{H})$-binding site. However, the gene sequence (Fig. 2) confirms an earlier suspicion based on the amino acid sequence of peptide fragments (Palmer et al., 1993), that, in the $\mathrm{R}$. rubrum enzyme, this Glu is replaced with a Gln (PntAA, position 247) and is unlikely to be involved in catalysis. Changing the equivalent Glu in the $E$. coli enzyme by site-directed mutagenesis led to the same conclusion (Glavas et al., 1993). Other acidic residues in the same region are conserved in the bacterial enzymes (PntAA-Glu241 and PntAA-Glu249) but, again, site-directed mutagenesis of E. coli $\mathrm{H}^{+}$-Thase indicated that they are non-essential (Glavas et al., 1993). It is possible that this region of 


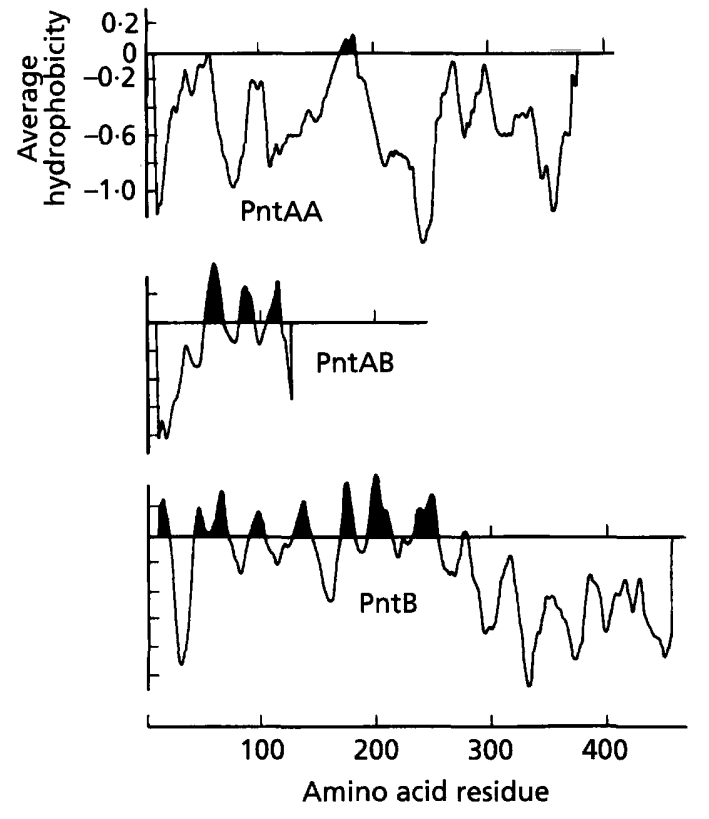

Fig. 5. Hydropathic profiles of the PntAA, PntAB and PntB polypeptides of $\mathrm{H}^{+}$-Thase from $R$. rubrum derived using the parameters described by Von Heijne (1992)-see Methods. A value of 0.05 is added to each hydropathicity score to scale the plot so that shaded regions indicate putative transmembrane helices.

domain $\mathrm{I}$, just downstream of the $\mathrm{NAD}(\mathrm{H})$-binding site and rich in polar and charged residues (Fig. 5), corresponds to a flexible loop which is susceptible to modification by proteases and, in some conditions, by dicyclohexylcarbodiimide and [ $p$-(fluorosulphonyl)benzoyl] $-5^{\prime}$ adenosine. Thus, the peptide bond C-terminal to a conserved Lys (residue 237 in PntAA) is sensitive to trypsin in the enzyme from $R$. rubrum (Cunningham $e t$ al., 1992a), E. coli (Tong et al., 1991) and bovine mitochondria (Yamaguchi et al., 1990). Furthermore, in PntAA a neighbouring peptide bond, Lys227-Thr228, is very sensitive to the endoprotease Lys-C (apparently not investigated in the E. coli and bovine enzymes). When the native purified soluble subunit of $R$. rubrum $\mathrm{H}^{+}$-Thase was treated with concentrations of trypsin low enough to give only two polypeptides on SDS-PAGE (apparent molecular mass $29 \mathrm{kDa}$ and $19 \mathrm{kDa}$, thus corresponding to cleavage at Lys237-Glu238), with only minimal contamination from other fragments, its capacity to reconstitute transhydrogenase activity to depleted chromatophore membranes was severely inhibited. However, the data of Fig. 6 show that the trypsin-treated protein blocked reconstitution by untreated material. Thus, a crude preparation of soluble subunit was used to titrate light-driven transhydrogenation to about $90 \%$ of full activity (the 'crude' enzyme was used because pure protein is difficult to prepare in substantial quantities; see Cunningham $e t$ al., 1992a). As expected, further addition of pure soluble subunit led to complete reconstitution. However, in contrast, further addition of the trypsinized material led to inhibition of transhydrogenation. Evi-

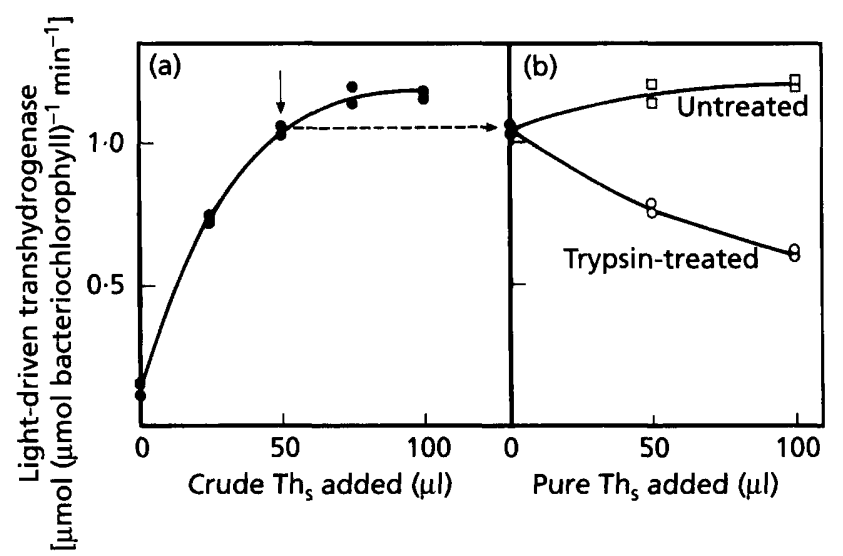

Fig. 6. The two tryptic fragments of the soluble subunit of $\mathrm{H}^{+}$Thase from $R$. rubrum block reconstitution of light-driven transhydrogenation by the intact subunit and depleted chromatophore membranes. In (a), $\mathrm{C}_{\mathrm{T}}$-particles (bacteriochlorophyll to a final concentration of $10 \mu \mathrm{M}$ ) in $2.5 \mathrm{ml}$ $125 \mathrm{mM}$ sucrose, $2.7 \mathrm{mM} \mathrm{MgCl}, 60 \mu \mathrm{M}$ thio-NADP ${ }^{+}, 250 \mu \mathrm{M}$ $\mathrm{NADH}, 44 \mathrm{mM}$ Tris/ $\mathrm{HCl} \mathrm{pH} \mathrm{8.0,} \mathrm{were} \mathrm{incubated} \mathrm{for} \mathrm{1-2} \mathrm{min} \mathrm{with}$ a crude preparation ('type II') of soluble subunit (10 mg protein $\mathrm{ml}^{-1}$ ), as shown, and then assayed for lightdriven transhydrogenation at $30^{\circ} \mathrm{C}$. The incubation conditions indicated by the arrow were used as a basis for the experiments shown in (b). Here, additional purified soluble subunit ( $30 \mu \mathrm{g}$ protein $\mathrm{ml}^{-1}$ ), either trypsin-treated (see Methods) or untreated, was added, as shown. In control experiments, (i) addition of trypsin and trypsin-inhibitor to $C_{T}$-particles in the presence of crude soluble protein to give $90 \%$ reconstitution, but in the absence of purified protein, decreased the rate of transhydrogenation by only $7 \%$, (ii) $50 \mu \mathrm{l}$ of untreated, purified soluble subunit added to $C_{T}$-particles (in the absence of crude protein) gave transhydrogenation rates of $0.90 \mu \mathrm{mol}(\mu \mathrm{mol}$ bacteriochlorophyll) ${ }^{-1} \mathrm{~min}^{-1}$, and (iii) $50 \mu \mathrm{l}$ of trypsin-treated, purified soluble subunit added to $C_{T}$-particles (in the absence of pure protein) gave transhydrogenation rates of $0.37 \mu \mathrm{mol}$ ( $\mu \mathrm{mol}^{-1}$ bacteriochlorophyll) ${ }^{-1} \mathrm{~min}^{-1}$.

dently, at least one of the two polypeptide fragments retains structural integrity and is capable of docking with the membrane component of the enzyme, thus competing with the intact protein for binding sites. It proved difficult to separate the $19 \mathrm{kDa}$ and $29 \mathrm{kDa}$ polypeptides, even by HPLC, with the small amounts of material that are available.

Information on the location of the $\mathrm{NADP}(\mathrm{H})$-binding site of $\mathrm{H}^{+}$-Thase is rather less clear, although it seems to be in domain III of the enzyme (Yamaguchi \& Hatefi, 1993). The Gly residue at $\beta 314$, which is replaced by a Glu in the RH1 mutant of E. coli $\mathrm{H}^{+}$-Thase (Ahmad et al., 1993), is conserved in the R. rubrum enzyme (PntB-Gly315). In the RH1 mutant, the influence of $\mathrm{NADP}(\mathrm{H})$ on the pattern of polypeptides generated by trypsin treatment is lost (Ahmad et al., 1993). The Tyr residue, which has been implicated in NADP)H) binding because of its reactivity in the mitochondrial enzyme with [ $p$-(fluorosulphonyl)benzoyl]-5'-adenosine (Wakabayashi \& Hatefi, 1987a) and 8-azido-AMP (Hu et al., 1992), despite the fact that, strictly, both are $\mathrm{NAD}(\mathrm{H})$ analogues, is conserved in 
R. rubrum $\mathrm{H}^{+}$-Thase (PntB-432). Note that replacement of this residue by site-directed mutagenesis shows that it is not essential (Olausson et al., 1993).

\section{Evolutionary relationships between alanine dehydrogenase and $\mathrm{H}^{+}$-Thase}

A strong sequence similarity between the alanine dehydrogenases of two species of Bacillus and domain I of the $\mathrm{H}^{+}$-Thases of $E$. coli and bovine mitochondria was previously reported (Cunningham et al., 1992a). There is $29 \%$ identity between PntAA from R. rubrum and alanine dehydrogenase from Bacillus stearothermopbilus (Kuroda et al., 1990 - see Fig. 3).

It is evident that, despite the different polypeptide composition, the order of translation of the domains within the transcriptional unit of $\mathrm{H}^{+}$-Thase is the same in the R. rubrum, E. coli and bovine systems (I > IIa $>$ IIb $>$ III) but is different in Ei. tenella (IIb $>$ III $>$ I $>$ IIa ; Kramer et al., 1993). It is likely that gene fusions and rearrangements have given rise to the different organizations. In view of the sequence similarity between domain $I$ and alanine dehydrogenase, it is possible that the $R$. rubrum structure represents the most primitive of those studied so far. Thus, following suggestions for the evolution of other membrane proteins (Walker, 1992), we suppose that an $\mathrm{R}$. rubrum-like $\mathrm{H}^{+}$-Thase would have originated from an association between an ancestor of alanine dehydrogenase (becoming domain I) with an ancestor of the membrane-located domain IIa and domain IIb/III proteins. Subsequent clustering of the genes and fusion between domains I and the IIa protein would have given the E. coli organization, and further fusion between domains IIa and IIb would have given the bovine organization. A different gene clustering arrangement or a transposition of the gene segments corresponding to domain I-IIa and domain IIb-III followed by fusion would have given an Ei. tenella-like protein.

\section{ACKNOWLEDGEMENTS}

We are grateful to the Science and Engineering Research Council for financial support and to Dr John Fox and his colleagues in Alta Bioscience for assistance with the $\mathrm{N}$-terminal amino acid sequencing, the synthesis of oligonucleotides and the automated DNA sequencing. The automatic DNA sequencer was purchased with a grant from the Wellcome Trust.

\section{REFERENCES}

Adams, M. D., Dubnick, M., Kerlavage, A. R., Moreno, R., Kelley, J. M., Utterback, T. R., Nagle, J. W., Fields, C. \& Venter, J. C. (1992). Sequence identification of 2375 human brain genes. Nature 355, 632-634.

Ahmad, S., Glavas, N. A. \& Bragg, P. D. (1992). A mutation at Gly314 of the $\beta$ subunit of the Escherichia coli pyridine nucleotide transhydrogenase abolishes activity and affects the NADP(H)induced conformational change. Eur J Biochem 207, 733-739.

Birnboim, H. C. \& Doly, J. (1979). A rapid alkaline extraction procedure for screening recombinant plasmid DNA. Nucleic Acids Res 7, 1513-1523.
Clarke, D. M., Loo, T. W., Gillam, S. \& Bragg, P. D. (1986). Nucleotide sequence of the pnt $A$ and $p n t B$ genes encoding the pyridine nucleotide transhydrogenase of Escherichia coli. Eur $J$ Biochem 158, 647-653.

Clayton, R. K. (1963). Towards the isolation of a photochemical reaction centre in Rbodopseudomonas capsulata. Biochim Biopbys Acta 73, 312-323.

Cunningham, I. J., Williams, R., Palmer, T., Thomas, C. M. \& Jackson, J. B. (1992a). The relation between the soluble factor associated with $\mathrm{H}^{+}$-transhydrogenase of Rhodospirillum rubrum and the enzyme from mitochondria and Escherichia coli. Biochim Biophys Acta 1100, 332-338.

Cunningham, I. J., Baker, J. A. \& Jackson, J. B. (1992b). Reaction between the soluble and membrane-associated proteins of the transhydrogenase of Rbodospirillum rubrum. Biochim Biophys Acta 1101, 345-352.

Devereux, J., Haeberli, P. \& Smithies, O. (1984). A comprehensive set of sequence analysis programs for the VAX. Nucleic Acids Res 12, 387-395.

Feinberg, A. P. \& Vogelstein, B. (1983). A technique for radiolabelling DNA restriction endonuclease fragments to high specific activity. Anal Biochem 132, 6-13.

Fisher, R. R. \& Guillory, R. J. (1971a). Resolution of enzymes catalyzing energy-linked transhydrogenation - interaction of transhydrogenase factor with the Rhodospirillum rubrum chromatophore membrane. J Biol Chem 246, 4679-4686.

Fisher, R. R. \& Guillory, R. J. (1971b). Resolution of enzymes catalyzing energy-linked transhydrogenation-preparation and properties of Rbodospirillum rubrum transhydrogenase factor. J Biol Chem 246, 4687-4693.

Fitzmaurice, W. P., Saari, L. L., Lowery, R. G., Ludden, P. W. \& Roberts, G. P. (1989). Genes coding for the reversible ADPribosylation system of dinitrogenase reductase from Rhodospirillum rubrum. Mol \& Gen Genet 218, 340-347.

Glavas, N., Ahmad, S., Bragg, P. D., Olausson, T. \& Rydstrom, J. (1993). Aspartic acid residues in Escherichia coli transhydrogenase and the exchange of these by site-specific mutagenesis. I Biol Chem 268, 14125-14130.

Harley, C. B. \& Reynolds, R. P. (1987). Analysis of Escherichia coli promoter sequences. Nucleic Acids Res 15, 2343-2361.

Hatefi, Y. \& Yamaguchi, M. (1992). Energy-transducing nicotinamide nucleotide transhydrogenase. In Molecular Mechanisms in Bioenergetics, pp. 265-281. Edited by L. Ernster. Amsterdam: Elsevier.

Hu, P. S., Persson, B., Hoog, J. O., Jornvall, H., Hartog, A. F., Berden, J. A., Holmberg, E. \& Rydstrom, J. (1992). Energy-linked transhydrogenase. Characterisation of a nucleotide-binding sequence in nicotinamide nucleotide transhydrogenase from beef heart. Biochim Biophys Acta 1102, 19-29.

Jackson, J. B. (1991). The proton-translocating nicotinamide adenine dinucleotide transhydrogenase. J Bioenerg Biomembr 23, 715-741.

Kramer, R. A., Tomchak, L. A., McAndrew, S. J., Becker, K., Hug, D., Pasamontes, L. \& Humbelin, M. (1993). An Eimeria tenella gene encoding a protein with homology to the nucleotide transhydrogenase of Escherichia coli and bovine mitochondria. Mol Biochem Parasitol 60, 327-332.

Kuroda, S., Tanizawa, K., Sakamoto, Y., Tanaka, H. \& Soda, K. (1990). Alanine dehydrogenases from two Bacillus species with distinct thermostabilities: molecular cloning, DNA and protein sequence determination and structural comparison with other 
NAD(P)-dependent dehydrogenases. Biochemistry 29, 1009 1015.

Kustu, S., Santero, E., Keener, J., Topham, D. \& Weiss, D. (1989). Expression of $\sigma-54(n \operatorname{tr} A)$-dependent genes is probably united by a common mechanism. Microbiol Rev 53, 367-376.

Kyte, J. \& Doolittle, R. F. (1982). A simple method for displaying the hydrophobic character of a protein. J Mol Biol 157, 105-132.

Meissner, P. S., Sisk, W. P. \& Berman, M. L. (1989). Bacteriophage lambda cloning system for the construction of directional cDN.4 libraries. Proc Natl Acad Sci USA 84, 4171-4174.

Olausson, T., Hultman, T., Holmberg, E., Rydstrom, J., Ahmad, S., Glavas, N. A. \& Bragg, P. D. (1993). Site-directed mutagenesis of tyrosine residues at nicotinamide nucleotide-binding sites of Escherichia coli transhydrogenase. Biochemistry 32, 13237-13244.

Palmer, T. \& Jackson, J. B. (1992). Nicotinamide nucleotide transhydrogenase from Rhodobacter capsulatus; the $\mathrm{H}^{+} / \mathrm{H}^{12}$-ratio and the activation state of the enzyme during reduction of acetyl pyridine adenine dinucleotide. Biochim Biopbys Acta 1099, 157-162.

Palmer, T., Williams, R., Cotton, N. P. J., Thomas, C. M. \& Jackson, J. B. (1993). Inhibition of proton-translocating transhydrogenase from photosynthetic bacteria by $N, N$-dicyclohexylcarbodiimide. Eur J Biocbem 211, 663-669.

Platt, T. (1986). Transcription termination and the regulation of gene expression. Annu Rev Biochem 55, 339-372.

Rydstrom, J., Persson, B. \& Carlenor, E. (1987). Transhydrogenase linked to pyridine nucleotides. In Pyridine Nucleotide Coenzymes: Chemical, Biochemical, and Medical Aspects, vol. 2B, pp. 433-460. Edited by D. Dolphin, R. Poulson \& O. Avramovic. New York: John Wiley.

Sambrook, J., Fritsch, E. F. \& Maniatis, T. (1989). Molecular Cloning: a Laboratory Manual, 2nd edn. Cold Spring Harbor, NY: Cold Spring Harbor Laboratory.

Sanger, F., Nicklen, S. \& Coulson, A. R. (1977). DNA sequencing with chain-terminating inhibitors. Proc Natl Acad Sci US 1 74, $5463-5467$.

Tong, R. C. W., Glavas, N. A. \& Bragg, P. D. (1991). Topological analysis of the pyridine nucleotide transhydrogenase of E. coli using proteolytic enzymes. Biochim Biophys Acta 1080, 19-28.
Von Heijne, G. (1992). Membrane protein structure prediction. Hydrophobicity analysis and the positive-inside rule. J Mol Biol 225 , 487-494.

Von Heijne, G. (1986). A new method for predicting signal sequence cleavage sites. Nucleic Acids Res 14, 4683-4690.

Wakabayashi, S. \& Hatefi, Y. (1987a). Amino acid sequence of the $\mathrm{NAD}(\mathrm{H})$-binding region of the mitochondrial nicotinamide nucleotide transhydrogenase modified by $N, N^{\prime}$-dicyclohexylcarbodiimide. Biochem Int 15, 667-675.

Wakabayashi, S. \& Hatefi, Y. (1987b). Characterization of the substrate-binding sites of the mitochondrial nicotinamide nucleotide transhydrogenase. Biochem Int 15, 915-924.

Walker, J. E. (1992). The NADH:ubiquinone oxidoreductase (complex I) of respiratory chains. $Q$ Rev Biophys 25, 253-324.

Weaver, P. F., Wall, J. D. \& Gest, H. (1975). Characterisation of Rhodopseudomonas capsulata. Arch Microbiol 105, 207-216.

Wierenga, R. K., Terpstra, P. \& Hol, W. G. J. (1986). Prediction of the occurrence of the ADP-binding $\beta-\alpha-\beta$-fold in proteins using an amino acid sequence fingerprint. J Membr Biol 187, 101-107.

Yamaguchi, M. \& Hatefi, Y. (1991). Mitochondrial energy linked nicotinamide nucleotide transhydrogenase. Membrane topography of the bovine enzyme. J Biol Chem 266, 5728-5735.

Yamaguchi, M. \& Hatefi, Y. (1993). Energy-transducing nicotinamide nucleotide transhydrogenase. Nucleotide-binding properties of the purified enzyme and proteolytic fragments. I Biol Chem 268, 17871-17877.

Yamaguchi, M., Hatefi, Y., Trach, K. \& Hoch, J. A. (1988). The primary structure of the mitochondrial energy-linked nicotinamide nucleotide transhydrogenase deduced from the sequence of $\mathrm{cDNA}$ clones. J Biol Chem 263, 2761-2767.

Yamaguchi, M., Wakabayashi, S. \& Hatefi, Y. (1990). Mitochondrial energy-linked nicotinamide nucleotide transhydrogenase; effect of substrates on the sensitivity of the enzyme to trypsin and identification of tryptic cleavage sites. Biochemistry 29, 4136-4143.

Received 19 January 1994; revised 21 February 1994; accepted 28 February 1994. 